\title{
COMPUTERS AND FOREIGN LANGUAGE INSTRUCTION John Russell
}

Computers were originally invented to facilitate the manipulation of numbers and this remains their major function with which they have become so necessary to our modern life. What is of greater interest to Language teachers, however, is their ability to compare one string of impulses with another. These symbols need not be numbers, but can be letters of the alphabet or simply indicate whatever values is assigned to them. Obviously, one can use the computer to manipulate words according to a given pattern and then compare the answer produced with the desired answer. Thus the computer can be used as a tutor to give the student new information (although the printed page is probably still more effective), to drill him or her in the manipulation of the target language to acquire the skills of reading and writing and, to a certain extent, that of listening and, again with a big question mark concerning economy, culture. Despite ever more promising experiments, it does not yet seem feasible to use the computer for teaching speaking skills.

When computers first entered education on a relatively broad basis in the early sixties, the term computer-assisted instruction (CAI) was coined. Perhaps influenced by the academic climate of the times, some educators sought also to introduce computer-assisted learning (CAL). Others defined $\mathrm{CAl}$ as computer-administered instruction, sometimes limiting the new coinage to courses given by the computer without any classroom instruction; the current version of this seems to by CMI, standing for computer-managed instruction. One of the latest entries is CECOLE (pronounced 'seafull') coined by Maj. Towne of the Air Force Academy, who derived it from 'computer-executed, game-oriented learning experience'. Commendable as each of these may be, they all fit under the rubric of CAI.

The interface of computers and education came to FLs in the mid-sixties when IBM approached a number of universities with various experiments in mind. One such experiment took place at the State University of New York (Suny) in Stony Brook where subsequently CAI became a standard component of the beginning German course; it remained such for about a decade until one of the first shocks of the financial crunch caused the unplugging and return of our 1500 to IBM. Even with the most felicitous accounting it had been running at ca. $\$ 4$ per student hour and thus was obviously vulnerable. Although the cancelling of our 'experiment' came as no surprise, it left those concerned less than pleased. In this relatively brief experience the faculty had come to regard CAl as an invaluable tutor for the students, serving as a better drillmaster than the teacher could, and an excellent method of getting grammar discussion out of the classroom. The students also liked it, often better than they did teachers for drilling since the computer could wait hours for an 
answer without losing patience and then correct each error as it appeared. The technical reduction of learning errors benefited everyone.

Fortunately advances in microelectronics and information technology helped solve the problem of expensive equipment. By the mid-seventies prices and size had dropped dramatically while capabilities had increased greatly. One result was the emergence of the microcomputer which again made CAl for the FLs possible, even given the state of the economic world.

The situation on a typical campus which will indeed have a main frame and mini computers. These were used for a number of purposes, principally (of course) administration and funded research. If there was any capability left for instruction, it understandably dominated by the Computer Science majors. The advantages of using the mainframe are obvious: its size offered a number of capabilities which no micro was able to match. Moreover, the equipment required a staff which offered a great deal of assistance to students \& faculty. If the situation is propitious, all you would have to do is tell a programmer what you want and then supply the appropriate materials to plug into the program created for you. Then students are sent to the available terminals to do assigned or optional drills. This scenario assumes that the computer center staff and their hardware are underutilized. Neither of these assumptions should be taken lightly.

Leaving campus politics and paranoia aside, an overwhelming argument against the mainframe is the question of graphics. Assuming one has gained both programming time and access, to the computer, there is the significant problem of having the computer generate the various diacritics needed for such foreign languages as Slavic or even for exotic languages which require whole new alphabets or syllabaries. Again, large computers are capable of doing all sorts of splendid things, among which is often an ability to generate such exotic graphics, but that would be for in-house use. What is more probably involved would be a modification of the character set within any terminal(s) one might plan to use. This is usually expensive and given the size of the clientele intended, rarely regarded as a justifiable modification. One would probably be asked to make do with the existing character set especially when the changes are few (e.g., as with the Cermanic Languages). For those using more diacritics (e.g., the Romance Languages), one would probably have to either ignore the diacritics or, employ unused characters in postposition and ask the students to believe that $n \$$ really means $n$.

A final argument against the mainframe is one that is not theoretically necessary, but seems to be all but unavoidable in practice with so many capabilities at hand, mainframe programming tends to be unique: each comp center has its own problems for which unique answers are found and these color all programming. There is 
nothing wrong with this except that when much time, money and effort are expended to create programs for relatively small audiences, it seems deplorable that the resulting product is so site-specific that it won't run satisfactorily at a campus with a nearly indentical hardware configuration. The field is sufficiently constrained so language teachers need to focus on transferability or portability--both terms are used in order to have programs which are more effective.

Before discussing recommendations for microprocesses intended for the FLs, it is important to point out some general considerations. There are three leading micros in the US (and the world), which are the TRS-80 (Radio Shack), the Apple and the Commodore PET, along with an everexpanding number of other makes such as Atari, Exidy, not to mention IBM, down to the Sinclair, available in kit form for ca. $\$ 150$. All of these micros offer a means of entering data, typically a keyboard or pressure plate, along with a microprocessor and the means of storing and retrieving data. Either present or to be added on is the capability for a visual check of the information by means of a TV monitor. Most micros can also be made to print out via a typewriter but this is rarely a first choice since the cathode ray tube (CRT) is sufficient for programming and of dubious value for student use unless one really wants to have a record of all data errors as well as his triumphs. The amount of paper strewn about can become a major nuisance as well as a considerable expense.

Another feature either built-in or to be added is the means for saving data or entering them from without. This is typically a cassette drive (ca. \$75) for the casual user or a (double) disk drive for the serious user (\$400-1,000¥). The big advantage of the latter is its speed of operation: it can load a typical student lesson in a few seconds where the cassette drive will take two or three minutes. (For the affluent, there are also wiring networks available with which one disk drive can load a dozen or so micros so that one would duplicate the flexibility of the conventional language lab, even to monitoring on the master console what the student is doing at a particular station.)

Which micro should one purchase? The answer to this question is, of course, constrained by what one wants to do, how it must be done, and how many dollars are available to do it. With enough money almost any micro can be modified to do whatever is needed. Adding on or modifying, however, tends to be relatively costly so first consideration should go to finding that particular micro which does best what one wants to do.

FL teachers may not envision their students advancing to the point where they will need word processing but this may be exactly what English teachers may require for the use of computers in the teaching of college composition. Similarly, one may find that color capability is an unjustifiable extra expense, but a colleague from the Social Sciences may deem it vital for the construction of bar graphs. 
The question of other users also plays a role in the decision concerning a printer. Although one may be content with the CRT display, a printer is very useful. You could probably do very well with the bottom of the line (ca. $\$ 300$ ) but for a few hundred more the printer will approach 'letter quality'. One needs only to couple this printer to a micro, add a word processing program, and this will win the hearts of any number of secretaries.

Before any further comments on specific micros, consider again the problem of foreign diacritics. The computing world is English-speaking and in a dialog with a micro, one will use either English or abbreviations of familiar words. (It is possible to bypass 'normal' language and address the computer with alphanumeric combinations called machine language, but this is a level of sophistication which should not influence one's choice of a micro. Nor should one pay attention to a salesman when he tries to tell you how superior his dialect of BASIC is. The differences are insignificant.) There are two relatively easy ways to alter the graphics set of a given micro. One of these is called user-definable graphics and is built into some computers, such as the Apple or the Exidy. With a good deal of patience, the user can write a program which (re)defines the image which appears when a specific key or keys are hit. Such programs can be saved, however, and reused with any appropriate language program; they also are transferable to any other micro of the same make. An alternative method takes such a program and turns it into a $\$ 4$ substitute chip known as an EPROM. The manufacturer's graphics chip is pulled and the substitute is inserted. If the micro has a large number of keys--e.g. not only a keyboard but also a numbers pad--one may be able to get onto one chip all the characters needed for the foreign languages the institution teaches. Such a substitute chip means that your FL characters are always available and do not take up any of the RAM into which you are trying to put your programs. It should be noted, however, that a number of manufacturers store their graphics in various unused nooks and crannies of the ROM so that the substitute chip is often not a possible solution to the problem.

With the graphics problem still in mind, consider to the micro market. Convenient as it is to have a Radio Shack around every corner, one would not recommend the TRS- 80 because the manufacturer warns against trying to change the graphics. The same can be said allegedly of Atari. The choice of a micro for the FLs appears essentially to be a choice between the Apple and the PET. There are considerations beyond the simple one of price. If one trains, secondary school teachers, or teach at that level or even at the elementary level (if FLES is still alive anywhere), one may find excellent uses for both color or sound. If so, head for the Apple or, if a 24-character line is a problem, the VIC, which also has both capabilities built-in. 
Once puberty descends, languages are learned deductively a factor which has a great bearing on how to teach. Students want to learn the rules, apply them and then view the results. They neither need nor want to be titilated by having the stars and stripes wave across the screen accompanied by the "Stars and Stripes Forever" from within the computer whenever they get a high score. Such gimmicks are regarded as diversions in the negative sense.

Given all the foregoing considertions, one could opt for the PET, which indeed is limited to black and white as well as audio (sweet silence). Its built-in monitor is normally a great convenience but a nuisance when one wants to display these achievements away from home base. Commodore has always had a strong selling point for those in education: if one buys two of them a third one comes along free. Thus one can acquire a micro for about $\$ 2250$ with three $16 \mathrm{k}$ micros with cassette drives ready to plug in. It is politically expedient to be able to tell a chairman, dean or whomever that the equipment so desperately need has a unit price equivalent of an office typewriter.

Essentially comparable micros such as Apple, Exidy and Atari go for ca. $\$ 1,000$ and need some sort of display added. (To be fair, it should be noted that with these multiple purchases also bring significant price reductions.) If money is of little significance, one may well wish to go for Apple for which there is by far the largest selection of software for those interested in further uses such as game playing, word processing, bookkeeping and the like; however, unless a micro is very new to the marketplace, there is typically no lack of such programs sufficient to meet most needs.

Once one has decided on the computer needed, there remains the question of just how much memory the individual micro(s) should have. Although the first micros had only 1, 2 or $4 \mathrm{k}$ of memory, this has grown steadily cheaper and nowadays $16 \mathrm{k}$ seems to be the usual starting size. At the Suny Campus (which, please note, deliberately excludes both color and sound which eat up memory) $16 \mathrm{k}$ is more than enough to create any program that a student will be able to finish in one lab session, i.e. within 45-60 minutes. If one has the funding to set up a multi-station lab, this will probably require at least one micro with 32 or $48 \mathrm{k}$ for the odd chore requiring a lot of memory such as the compilation of a glossary for the beginning German CAl course.

There is also the area of programming which is apt to become a concern if one wants to put current technology to work in improving $\mathrm{FL}$ instruction. The degree of difficulty in programming is also dependent on just what one wishes to do: programming is simple but sophisticated tasks call for intelligent students with considerable experience. It isn't necessary to be a crackerjack programmer in order to create interesting and useful programs. With a brief exposure to BASIC, a language common to all micros, one can either write programs or edit other routines from programs of interest for one's own needs. 
There are a number of ways to get into programming. Initially, there are the manufacturer's handbooks; these vary in depth and detail but almost all are good as reference works when questions arise. Books on programming are available; one treats the micro specifically. There are also machine-specific courses which have accompanying cassettes or diskettes to aid in the acquisition of prompted hands-on experience. Also, help is no longer scarce. Where a decade or two ago the hobbyist crowd was still into hi-fi, they've now moved on to computers. A brief inquiry should identify these students knowledgeable--often quite so--in hardware (equipment), software (programs) and/or firmware (an in between stage where lengthy programs are put on a chip as an add-on to the micro).

In starting to write programs, it is best to have someone with experience near at hand. Even though the guidebooks do define the various commands and conventions, they can't predict and diagnose a specific mistake. Someone who has been there can save you much time and frustration. There is also a piece of firmware known as the Toolkit (ca. \$40) which helps to produce neat programs and to find and diagnose errors.

Once one has done even a little programming, further assistance is available through a large number of publications. These range from magazines such as BYTE and CREATIVE COMPUTING which attempt to cover the field, to those for a specific CPU (a single micro or micros from one manufacturer). Foreign language teachers should also able to consult foreign-language periodicals. For German readers there is the excellent monthly CHIP (Vogel Verlag Wurzburg), from which one can acquire not only programming help but also learn the gender and plural forms of the many, many words taken over from English in this area. There are also regional users' groups for those using a particular computer. At their meetings one will find all levels of expertise, much solace and the opportunity to acquire a number of programs at minimal expense. One should not overlook commercially available programs. Although those for the FLs are generally crude, childish and expensive, there are a number of excellent programs for teaching reading and spelling which one can adapt for $F L$ acquisition. The more expensive items tend to be 'locked' or 'bullet-proofed' so that one is not able to get into them, but this is still rare with educational programs. Finally, there are also 'magazines' which appear for specific computers in the form of cassettes or diskettes, each of which offers a variety of programs at a very reasonable price. For the PET there is CURSOR, which even has a German counterpart, SYNTAX, an excellent source of tidbits for the diligent student who has slugged his way through FL drills. Game directions in the $\mathrm{FL}$ guarantee a continuation of the learning process.

It is to get into the world of CAI for the FLs, but there are still worlds to be conquered. First of these is coupling the computer to sound. Present technology is more than adequate for having it give and correct dictation. There is also digitalized sound with at least 
one firm offering what amounts to a vocabulary that is not only visible but also audible. The applications imaginable for applied linguistics are practically unlimited. And for the truly adventurous, there remains computerized recognition and evaluation of speech, still unreliable but for how long? There are also a number of successful experiments using a micro coupled to a video disc. When this technique is refined and, more importantly, an inexpensive method is found for transfer from tape to laser disc, the wealth of visual material readily accessible for teaching language and culture will be staggering. Rapid advances in word processing have already produced computer chips containing tens of thousands of the most frequent English words. Although their editing abilities are limited to this point to spelling and syllabication, it's easy to predict that before long they will be able also to judge whether a sentence is grammatically correct. Since such chips are being prepared for the FLs, it shouldn't be long before we will be able to send a student to the computer for composition classes. The teacher will still be needed to seperate sense from nonsense, but the red-pencilling will have been done by the computer. All these developments and the many more to come mean that the light at the end of our long and murky fiscal tunnel comes from a genuine 'multi-media instruction', something that once meant that one used both tape recorder and slide projector! Now, one will be able to drill the students much more extensively and intensively in all the language skills. And, teachers will still be needed: however glorious the developments prove to be, the teacher is still going to be necessary, not only to design the programs, but also for the free interaction which is beyond simulation. Instruction will remain computer-assisted, not computerized.

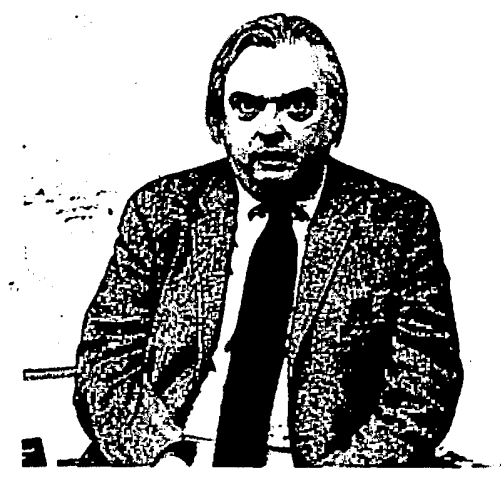

John R. Russell

State University of

New York at Stony Brook Stony Brook, NY 11794 

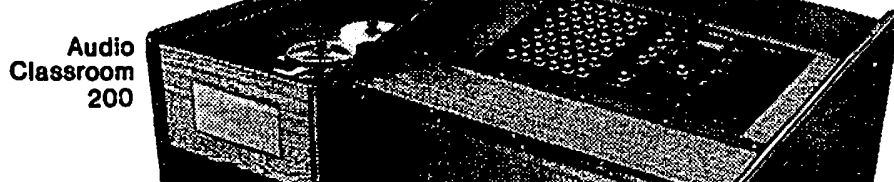

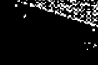

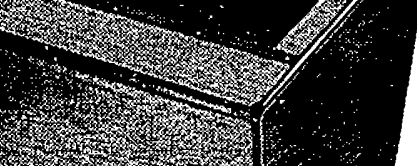

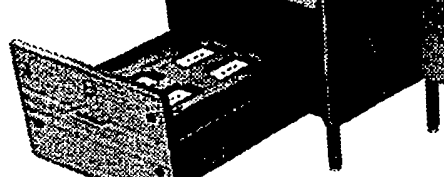
$-4$

Telex Communications, Inc. is a primar manufacturer of educational audio visual products, including Language Lab8. Over the years, the on-the-job pertormance record of these language lab products hes earned Teloxan enviable interity integrity. They are doveloped and producedin the U.S.A., and are sold,

$\frac{z}{2}$ installed and serviced by local factorytrained and authorized Telex Language Lab dealers.

Write for exciting details

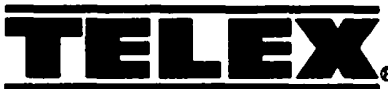

TELEX COMMUNICATIONS, INC.

9800 Aldrich Ave. So.. Minneapolis, MN 55420 U.S.A. Europe: 22. rue de la Légion-d'Honneur. 93200 St. Denis. France.
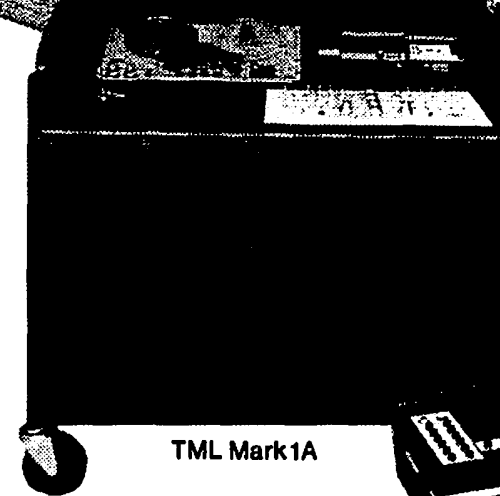

TML Mark1A

The versatile Audio Classre. om 200 is capable of all levels of languag's teaching. The economical, modular design allows easy expansion to accommodate up to ten program sources.

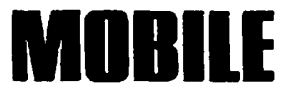

The Mark1A is a complete Levell language lab system self-contained in a mobile cabinet that is easily wheeled from room to room. A budget-saving alternative to the dedicated classroom. PORTARIE

The C-150 offers the lowest possible initial investment plus the flexibility to expano into a fuli, 36-position, Levelill system.

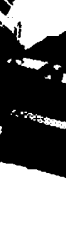

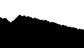

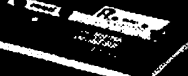

